\title{
Combined management strategies for the valorisation and reuse of defence cultural heritage and the promotion of sustainable cultural tourism
}

\author{
G. Quattrone \\ National Research Council of Italy, Institute of Atmospheric \\ Pollution Research, Italy
}

\begin{abstract}
The paper presents a research project aims to support the valorisation of the cultural patrimony of defence sites through a method of combined management of the cultural heritage both for the aspects linked to conservation and also those related to the valorisation, with the creation and the strengthening of the cultural systems. The methodology was applied in some contexts of Calabria Region in south of Italy.

The objectives of the project have been addressed to develop an integrated Action Plan for the management and standardization of defence cultural heritage sites through a direct and constant involvement of the community and the stakeholders, and through the use of methods and procedures for the creative re-use of architectures, territories and sustainable cultural tourism policies.

Expected outcomes were: 1) favouring the sustainable tourism applied to the defence cultural heritage; 2) expanding the potential of the defence cultural heritage research sector; 3 ) enhancing the dissemination of research results and news in the field of innovative management of defence cultural heritage; 4) increasing the visibility of the social and economic importance of the defence cultural heritage sector; 5) supporting educational and training programmes and activities and also transfer/exchange of knowledge in the sector; 6) developing a common framework of policies aimed at improving the protection, fruition and valorisation of defence cultural heritage; and 7) developing high-value tools and strategies applied to the defence cultural heritage management.

Keywords: cultural tourism, territorial planning, integrated management, conservation of cultural heritage, reuse.
\end{abstract}




\section{Introduction}

The presence of a detailed and well-structured cultural heritage supply represents a factor able to support pluralism, cultural growth, and facilitate social cohesion; it is also a useful condition that contributes to the improvement of the citizens' life quality, and especially to the economic development of the territory.

The research project aims to support the valorisation of the cultural patrimony through a method of combined management of the cultural heritage both for the aspects linked to conservation and also those related to the valorisation, with the creation and the strengthening of the cultural systems included in territorial areas characterized by a precise cultural-historic identity, recognizable through the existence of a valuable cultural patrimony, and by the presence of individuals active in the recovery, conservation, and esteem of the patrimony sectors.

In order to value the cultural heritage, it is necessary to have a planning that involves both the authorities in charge of the management of the cultural heritage, and the industrial and service systems able to make the cultural tourism production chain competitive on the regional, national and international market [1]. Therefore the general objective of the project is the development of an integrated management strategy of the cultural heritage for its re-use and valorisation in conjunction with the dynamics that regulate the evolutionary processes of the landscape and with the concept of sustainable cultural tourism to sustain the public and private decision makers.

In addition the tourist phenomenon imposed itself internationally as one of the modalities of transformation of the territory which causes the major alterations to the natural ecosystems and environmental values, and the most significant loss of resources and identities of the local landscapes, while researching short-term income sources [2]. Therefore another objective of research is to verify and analyze the modalities of transformation and use of the cultural territory concerning the touristic development policies conducted by the local administrations and suggests the definition of a new type of planning and management that can integrate art, landscape and the quality urban and architectural system, oriented towards a typology of sustainable tourism; so it aims to establish an identity process. It is a new approach in the knowledge aware that a cultural territory should not only be examined scientifically, through conventional research systems, but also through an "artistic" and "poetic" essence of the sites, always linked to objective contexts and to the perceptions of social communities [3].

The research is important because the intervention strategies in the cultural patrimony sector, so far enforced in Europe, however, were not able to ensure an adequate valorisation of the cultural heritage, compatibly with the peculiarities of these resources and with sustainable solutions for the assets and the connected territory, oriented towards fruition. The lack of a combined management and the promotion of a strategy regarding the cultural patrimony, based on the engagement of the community and the stakeholders involved in the activities linked to the promotion and valorisation of the patrimony, represent a fact in all the European countries. Still cultural heritage is not a sufficiently enhanced 
resource, despite its remarkable consistency, its elevated attraction from a tourist point of view, and its ability to contribute to the reinforcement of the community's identity [4]. This patrimony can become a spark for the local economic development in as much as the resources and the services are integrated inside the areas with strong and recognizable territorial identities. Furthermore, always more frequently, many historic architectures and many valuable cultural landscapes are used for new purposes, because keeping their traditional function turns out to be too onerous, and this leads to a re-balance of the conditions in terms of management and subjected economies [5].

\section{The research context of the project}

Regarding the topics and geographic areas of study, the research studies the depressed coast areas, focusing on Calabria Region in Italy.

The Calabria region is a depressed region of the South with a cultural heritage that represents an immeasurable wealth. In the past this region has been subjected to drastic transformations under a strong human pressure and mass tourism which has determined an excessive and indiscriminate ground consumption and high risks for landscapes and cultural heritage due to the inadequacy of planning tools [6]. Regarding defence sites, these areas include important buildings and heritage constructions especially castles and coastal towers now degraded due to the strong depression caused by the explosion of beach low-cost mass-tourism outside the region. In all geographic areas of study, through the methodology to undergo, the intent for these areas is to supply an organic and coordinated set of multidisciplinary planning actions which aim to strengthen the cultural and landscape identity of the local communities, value the existing cultural heritage and increase the tourist attraction, activating new opportunities of sustainable development that are fully compatible with the environmental and landscapes qualities.

The coastal towers, the castles and the military fortifications in Calabria Region are numerous and scattered throughout the region.

The Calabria coastal towers were erected from around XII-XV sec., as part of a defensive plan against the Saracen forays on the Calabria coast that were causing great danger and loss of human life [7]. Collectively the coastal towers represented an effective fixed defence system (providing spotting and signalling) that integrated with the mobile defence system of galleys, and castles which were much incisive but more cumbersome. The locating of the towers in places with strategic vantage points made them an effective means to control the territory [8].

The castles of Calabria were, mainly, erected from XII-XIV sec., in the period medieval and by different dominations (Normans, Swabians, Angevins, Aragonese, etc.) The castles were located in every major center, in the key sites of the Region, on top of the old town for the control of territory. In many cases these are expansions of defensive structures existing or refundation to control the local population and the viability (terrestrial and maritime) in the sites largely anthropized in the early Middle Ages period [9]. 
The military fortification, in addition, represent another type of defence cultural heritage of Calabria Region, so-called "fortini" built during the Second World War for defensive reasons [10]. Restoration and conservation and valorisation project for the coastal towers, castles and military fortification defence regional heritage is conducted by Calabria Region into different programme as the "Integrated Coastal Zone Management", or the "Sustainable Environment", or the "POR Programme Agreement" (APQ) 2000-2006 "Agreement Framework Programme of Cultural Heritage" with which there were significant investments for the protection and enhancement of a significant part of the regional cultural heritage consists of Castles and towers and Military fortifications.

Interventions, many of which are in progress, involved a large number of assets, placing the emphasis on recovery and restoration interventions to enhance and networking. In the new programming period is necessary to complete the recovery and restoration interventions and activate the necessary actions to build, from this cultural heritage, a regional system of cultural attractions able to make the most attractive Calabria Region to visitors / tourists and operators in the sector of sustainable tourism and cultural industry [12].

The specific objective (5.2) of the POR FESR 2007-2013 consists in Valuing Assets and cultural activities which comparative advantage of Calabria to increase the attractiveness of the region, to strengthen social cohesion and improve the quality of life for residents.

The Operational Objective 5.2.1 consist in to protect, to systematize, enhance and make accessible the cultural heritage of Calabria Region consists from the areas cultural and archaeological parks, from the historic buildings monuments and important architectures, from Castles and Fortifications Military, from areas and facilities of industrial archaeology [12].

The objective of the strategy is the activation of an organic and integrated set of mutually consistent interventions aimed at the stewardship and valorisation of areas of high cultural and environmental importance. It does this by coordinating specific actions and through research into all possible synergies between the environment and adjoining areas, especially tourist ones, and favouring conditions to create new forms of employment [13].

Part of the interventions specifically regarding the coastal tower and castles restoration projects, are a series of works aimed at improving the accessibility and safety of the most abandoned and degraded buildings. The interventions fit into a sustainable tourism process, promoting the development of ecocompatible, archaeological and cultural forms of tourism. Fixed and functional activities will make these assets accessible, and improve understanding and appreciation of the important role that they have played historically. The economic effects for local areas and populations will be extremely important [13].

The coastal tower, castles and military fortifications works programme foresees a series of actions aimed to:

- implement safety measures on the defence buildings and their related areas;

- conserve the structures of the buildings; 
- preserve the memories and stories, however small, and the historic and cultural value of the locations;

- valorise individual buildings and highlight tourism itineraries (including through signposting and posters) to build a deeper understanding of the defensive system of Calabria, and at the same time to valorise and grow the cultural and environmental resources within the area;

- valorise jobs involving the coastal zone culture and landscape, with the aim of growing sustainable tourism in these areas and to provide economic opportunities which will limit the exodus of local populations;

- restore economic value to coastal zone and defence sites that have suffered from centuries of neglect and abandonment, rediscovering the potential of coastal assets as sources of energy for local and regional development.

In essence, the intention of the Calabria Region POR programme is to contribute the characteristic identity of each area. At the same time, the project aims to repay these areas for the important roles that they played, by turning them into crucial nodes of a larger re-discovery of the territorial history of the Region [13].

The end goal is for thriving coastal areas and defence sites with sustainable and quality tourism. The interventions will need to be complementary, systematic and coordinated, in order to achieve cultural recovery and, more generally, social and environmental restoration. Consequently, the use (through a range of tours and visits) and management of each individual building, is intended to form part of a larger integrated system, and must result from the constant and active cooperation between Calabria Region and the various stakeholders [14].

\section{The research methods}

In this context the defence cultural sites should be designed as new centers of territory to preserve and value in all its components.

The purpose of the research is to identify new methods and more suitable operative strategies of intervention, structured in pilot projects localized in precise areas of the territory of Calabria Region which aim to:

- Regenerate, re-use and value the defence cultural heritage through micro planning interventions which build relations between the spaces and generate identity processes;

- Suggest a model of sustainable tourist development for these areas;

- Satisfy the new requests in this sector, avoiding compromising the landscape/ environmental qualities and the historical/cultural sites;

- Promote an awareness and a widespread responsibility on the local landscape through participation processes;

- Support the opportunities of a tourism based on the sustainable valorisation of landscape and cultural resources of the territory, and the local identity peculiarities through the involvement of all the field operators and the local authorities in the planning process; 
- Develop survey methodologies and operative procedures to identify a repertory of elements and indicators for the measurement of the cultural identity in scientific terms, through the "Place Maker" method in relation to the cultural, historical and architectural heritage, and to the considered territory;

- Develop an integrated model for the knowledge of the defence cultural heritage which completes the potentialities of remote sensing, geographic information systems, socio-economic models and risk evaluation methods;

- Develop territorial marketing strategies and urban planning to know and control the territory through the defining of computerized technologies and geographical information systems;

- Identify strategies for the tourist fruition of the defence cultural heritage so to have an integrated territorial development, the creation of cultural itineraries and territorial marketing for the companies of the territory, through technologies that support the decision making;

- Propose guidelines for governance and development of innovative projects for the promotion of cultural heritage.

Functions assigned to the defence sites are conceived as part of the "integrated management".

The research activity is structured on the basis of six main axis which identify themes and goals: 1) operative defining of responsible tourism; 2) good practices for an integrated management of the defence cultural heritage; 3) classification of resources; 4) defining of tourist itineraries; 5) defining guidelines; 6) planning and realization of continuous e-learning educational itineraries.

The research advanced is also represented as a "service" performance to the local Institutions which can promote and/or realize the developed projects. The goal is to set-out the guidelines and define good planning and management practices promoting strategies for the local governance for the valorization of the cultural identity of the territories.

In the first phase, the activities for the conservation and enhancement of defence sites identified cannot be separated from those activated on other assets that constitute the heritage of the whole territory.

The Integrated Cultural System must be realized over the whole cultural heritage. It is therefore necessary that the start of the design of the Integrated Cultural System of Calabria Region is accompanied by an accurate strategic reflection and operational analysis and the study of other potential sites in the wider cultural system, and that this reflection produces promptly a continuous line of projects coordinated among themselves and responsibly shared [15].

Through a range of interactions with several stakeholders, collaborative and interdisciplinary approaches and knowledge exchange opportunities, it narrows the gap between cultural heritage research and the implementation of the resulting knowledge to solve problems relating to management of cultural heritage [16].

Projects should also develop links with several stakeholders in order to maximise the societal benefit of the research, in fact the project involves the achievement of periodic meetings with the population and with local 
stakeholders to explain the project and for their involvement in the management. Community participation will be through participatory methodologies for small groups, and through public meetings and conferences that to present and verify each phases of the project and its impacts [17].

\section{Benefits of research project}

The project propose innovative approaches and methods for the cultural heritage management and create effective actions to stimulate the exploitation of research results, and underpin cooperation between researchers, local government institutions and cultural heritage institutions for the application of identified solutions.

In particular the development of the Integrated Cultural System is an opportunity to the Calabria Region because:

- to promote defence cultural heritage of the Calabria Region;

- to expand and to diversify the cultural offerings and services to meet the needs and requirements of different types of public (residents, tourists);

- to identify forms of integrated management tailored to individual cultural institutions;

- to introduce additional services in institutions of culture also based on the use of new media technologies and digital records to the improvement of their quality and usability;

- to offer new cultural projects and project management skills aimed at management of the new integrated services for the culture;

- to encourage the development of local marketing actions with local stakeholders;

- to facilitate the spread of a socially responsible through the involvement of some important local businesses;

- to improve the entrepreneurial skills of the players in the world of art and culture through training and workshops dedicated;

- to make a significant contribution to local economic development with a consequent improvement in the quality of social life.

The project is an organizational model, reproducible for the promotion, valorization, preservation, fruition, use and management of the cultural historical-artistic heritage.

\section{Features of the management plan and results of project}

Among the peculiarities of the project -Integrated Cultural System of Calabria Region there are:

- the economic development statement; the innovation in the territory;

- the growth of the recognition of the Calabria Region as an area able to offer a system of cultural and tourist offer quality;

- the strengthening of the role of culture as an element of construction/reconstruction local identity to a greater identification between 
population and heritage; the choice to foster new forms of hybridization and creative contamination between different economic sectors but complementary interests towards cultural creativity;

- the strengthening and the enhancement of relations between the local territorial entities, public and private [18].

The results of project are:

- the transfer of knowledge for the diffusion of a culture aimed towards a responsible and sustainable tourism;

- the awareness of the local administrations and the community regards the themes of safeguard and esteem of the cultural landscapes and goods;

- the formulation of tourist development sceneries which include the duration need, referring to both the cultural and environmental/landscape sustainability, and the local participation;

- the planning of continuous e-learning educational courses for the technicians of the administrations and those who are enrolled in a professional register;

- the creation of participation laboratories;

- the promotion of cultural, natural and tourist places of interest, through a net of archeological, natural and monumental itineraries linked to historicalthematic paths afferent to the experimentation areas;

- the on-line realization and publication of a research database and a "good practice manual" for the governance, and the promotion of tourist development of the cultural heritage;

- the realization of a web site with the integration of an e-learning platform;

- the elaboration of a model for the management of the material and immaterial cultural heritage, that, when put to practice, will allow to bring added value to the role of "attractor" and "activator" of the cultural resources;

- the organization of seminars, scientific conferences and workshops;

- the scientific publications (books, scientific news articles, manuals with guidelines) and the scientific contributions in national and international conferences.

- the development of real economies linked to the enhancement of defence cultural heritage and environment and to support the growth of businesses and organizations (including the third sector) in the cultural sector;

- the identification of the distinctive elements of the Cultural System of Calabria Region in the future perspective of a joint District;

- the construction of an evaluation framework useful in the identification of territorial policies for the integration of the Integrated System of cultural heritage with other regional territorial systems;

- the growth in demand culture through the promotion of a wide range of offer;

- the transformation of the territory in an experimental laboratory for cultural attractor of tourist flows diversified and quality;

- the identification and evaluation of the impact on the spatial development of the regional expansion of the network of cultural identities and the environment, in particular through territorial strategies are able to: describe the physical and human resources through better organization, increased cooperation and adequate training. 
The outputs and outcomes from the project were highly valued and used by researchers and non-academic stakeholders, including SMEs, heritage owners, public administrations, enterprises and private economic stakeholders, local communities, considering the lack of a coordinated research structure in this specific and multidisciplinary sector and the high fragmentation of, national research programmes by identifying common strategic priorities for research to cultural heritage management [19].

\section{Conclusion}

The goal of this research project is to diversify the lines of economic development of territory and to encourage the development of a strong local identity through the creation of a cultural system that supports the valorisation of the cultural patrimony of defence sites. The proposed method combined the management of the cultural heritage both for the aspects linked to conservation and also those related to the valorisation, with the creation and the strengthening of the cultural systems.

The project develops an integrated Action Plan for the management and standardization of defence cultural heritage sites through a direct and constant involvement of the community and the stakeholders, and through the use of methods and procedures for the creative re-use of architectures, territories and sustainable cultural tourism policies. The Integrated Cultural System contemplate a number of synergistic actions that produce a wide range of services and marketing activity and communication as finalized as possible.

The cornerstone of the proposed strategy lies in a strong integration between the components of the territorial dimension of the cultural sector and the related sectors: tourism, cultural communication, marketing, research, education, university education, the vocational training, etc. The integration between different sectors and between different places is pursued through a "territorial specialization", or through the identification of places for the settlement of actions to value, for cultural entertainment activities, for the diffusion of itineraries for the location of training related.

\section{References}

[1] Cohen, E., Authenticity and commotization in tourism, Annals of Tourism Research, 15(3), pp. 371-86, 1988.

[2] Uzzell, D., Heritage, Interpretation. The natural and built environment, Belhaven: London and New York, 1998.

[3] Aas, C., Ladkin, A. \& Fletcher, J., Stakeholder collaboration and heritage management, Annals of Tourism Research, 32(1), Elsevier, pp. 28-48, January 2005.

[4] M Go, F. \& Govers, R., Integrated quality management for tourist destinations: a European perspective on achieving competitiveness, Tourism Management, 21(1), Elsevier, pp. 79-88, February 2000. 
[5] Vallega, A., Fundamentals of Integrated Coastal Management. Kluwer Academic Publishers: Dordrecht, The Netherlands, 1999.

[6] Valente, G., Storia della Calabria in Età Moderna, Alise: Chiaravalle Centrale, 1980.

[7] AA.VV., Castelli e città fortificate, Studi in onore di Marcello Grisotti: Rossano, 1994.

[8] Dragone, S. (ed.), Castelli e Torri di Calabria, Ied: Catanzaro, 1997.

[9] Pellicano Castagna, M., Le ultime intestazioni feudali in Calabria, Ied: Chiaravalle Centrale, 1978.

[10] Martin, J.M., L'impronta normanna sul territorio. I normanni popolo d'Europa 1030-1200, ed. M. D’Onofrio, Venezia, 1994.

[11] Paolino, F., Contributo per la storia di architetture di età federiciana.

[12] Programma Operativo Regione Calabria (POR) FESR 2007-2013. CCI N 2007 IT 161 PO 008. Catanzaro, September 2012.

[13] Quattrone G., Sviluppo rurale e urbano nei processi di pianificazione strategica in Calabria, Atti XXXV Conferenza AISRE, Padova, 2014.

[14] Vinci, I., Pianificazione strategica in contesti fragili, Alinea editrice, Firenze, 2010.

[15] Shepherd, R., Commodification, culture and tourism, Tourist Studies, 2(2), pp. 183-201, 2002.

[16] Cultural Coastal Landscape and Sustainable Tourist Development, Report of Prin Research, 2005, research financed by MIUR.

[17] Exploitation and enhancement of cultural heritage, Report of NET Heritage Research, PC.P05, 2008.

[18] Grabun, N., The evolution of tourist arts, Annales of Tourism Research, 11(3), pp. 393-419, 1984.

[19] Cultural Landscape, Report of CNR Research, PC.P06, 2007, research financed by CNR. 